\title{
CORRECTION
}

\section{OPTIMUM BOUNDS FOR THE DISTRIBUTIONS OF \\ MARTINGALES IN BANACH SPACES}

\author{
By IOSIF Pinelis \\ Annals of Probability (1994) 22 1679-1706
}

The correct expression of the optimal Bernstein bound in Theorems 3.3 and 8.6 in Pinelis (1994) must be

$$
\exp \left\{-\frac{r^{2}}{B^{2}+\Gamma r+B \sqrt{B^{2}+2 \Gamma r}}\right\}
$$

thus, the first entry of $\Gamma r$ here is missing in Pinelis (1994). Similarly, terms $2 \Gamma r$ and $\Gamma z$ are missing in the exponent on page 1705 in Pinelis (1994) and in Theorem 9 in Pinelis and Utev (1989), respectively. Hence, the expression $10^{-2 \sqrt{2}}<(1.5) \times 10^{-3}$ in Pinelis (1994) on line 4 of page 1705 must be replaced by $10^{-2}$.

Acknowledgment. I am grateful to Victor de la Peña for informing me about the mistake.

\section{REFERENCE}

Pinelis, I. F. and Utev, S. A. (1989). Exact exponential bounds for sums of independent random variables. Theory Probab. Appl. 34 340-2346.

Received December 1997. 